\title{
Evaluation of a Graphite-Polyurethane Composite Electrode Modified with Copper Nanoparticles as an Amperometric Flow Detector in a Wall-Jet System for the Determination of Cysteine
}

\author{
Isabela A. Mattioli, ${ }^{a}$ Leticia F. L. Schildt, ${ }^{a}$ Priscila Cervini, ${ }^{a}$ Thalita R. Saciloto ${ }^{a}$ and \\ Éder T. G. Cavalheiro ${ }^{\circledR *} * a$
}

${ }^{a}$ Instituto de Química de São Carlos, Universidade de São Paulo, Av. Trabalhador São-Carlense, 400, 13566-590 São Carlos-SP, Brazil

\begin{abstract}
A graphite-polyurethane composite electrode (GPUE) was modified by electrodeposition of copper nanoparticles (CuNP) followed by electrochemical treatment in $\mathrm{NaOH}$ (GPUE-CuNP), in order to prepare an amperometric sensor for the determination of cysteine (Cys). Cyclic votammograms of Cys solutions at GPUE-CuNP allowed the description of a sequence of electrochemical reactions involving Cys oxidation and $\mathrm{Cu}^{0} / \mathrm{Cu}^{+}$equilibrium, generating a stable $\mathrm{Cys}-\mathrm{Cu}^{+}$complex. The presence of these nanoparticles was confirmed by scanning electron microscopy (SEM) and energy dispersive X-ray spectroscopy (EDX) data. Hence, the developed device was then used as a Cys amperometric flow detector in a wall-jet system, after evaluation of flow injection parameters in an undescribed approach. In this system, a limit of detection (LOD) of $4.24 \mu \mathrm{mol} \mathrm{L} \mathrm{L}^{-1}$ was obtained with an analytical frequency of 36 determinations $\mathrm{h}^{-1}$. Intra-day and inter-day reproducibility and repeatability of the modified surface was evaluated. Then the GPUE-CuNP performance was investigated in the determination of Cys content in food supplements. Interference tests were carried out with pyridoxine, ascorbic acid, tryptophan and $\mathrm{SO}_{4}{ }^{2-}$ ions. The main interference was attributed to the interaction of some of these substances with copper oxides.
\end{abstract}

Keywords: graphite-polyurethane electrode, copper nanoparticles, cysteine, wall-jet

\section{Introduction}

L-Cysteine (2-amino-3-mercapto propanoic acid, Cys) is a sulfur containing amino acid with considerable importance in biological systems due to its biocatalytic activity, detoxification capacity and its involvement in many other important biological processes. Cys presents a thiol group in its side chain and is mostly found in proteins and glutathione. It is also known as one of the 20 common amino acids constituents of proteins and enzymes in the human metabolism. Changes in Cys content in the body can be related to nervous and mental diseases, such as Alzheimer's and Parkinson's. ${ }^{1-3}$

When exposed to air or in certain physiological conditions Cys is easily oxidized to cystine, a dimer composed of two cysteine molecules put together by $\mathrm{S}-\mathrm{S}$ bond. Due to this ability of thiols group of being rapidly oxidized, cysteine presents antioxidant properties. ${ }^{1-3}$

*e-mail: cavalheiro@iqsc.usp.br
Cys can undergo the ionization of its $\alpha$-carboxyl group with $\mathrm{p} K_{\mathrm{a} 1}=2.0$ and $\alpha$-ammonium group, with $\mathrm{p} K_{\mathrm{a} 2}=8.2 .^{4}$ Cys structural formula is represented in Figure 1.<smiles>NC(CCS)C(=O)O</smiles>

Figure 1. Planar representation of Cys chemical structure.

Thus, controlling the content of this amino acid in body fluids, pharmaceuticals and food supplements is of relevance and several analytical methods for Cys determination have been described. Literature describes such determination using spectrophotometric, ${ }^{5-7}$ spectrofluorimetric, ${ }^{3,8}$ chromatographic, ${ }^{9,10}$ voltammetric, ${ }^{2,11,12}$ capillary electrophoresis ${ }^{13}$ and amperometric ${ }^{1,14,15}$ procedures. Electrochemical methods present many advantages in comparison to other analytical methods, as simplicity, 
high sensitivity, easiness of sample preparation, low cost and faster analysis. ${ }^{11}$

Regarding Cys determination using amperometric methods, Tseng et al. ${ }^{1}$ used a glassy carbon electrode stabilized with $\mathrm{In}^{3+}$ hexacyanoferrate for Cys amperometric detection, obtaining a limit of detection (LOD) of $50 \mu \mathrm{mol} \mathrm{L}{ }^{-1}$. Although reproducible measurements with low standard deviations were obtained, the Cys detection was carried out under a highly positive potential of $1.2 \mathrm{~V}$ (vs. Ag/AgCl). ${ }^{1}$ Kubota and co-workers ${ }^{14}$ used a glassy carbon electrode modified with multi-walled carbon nanoubes and a metallopolymer for Cys amperometric detection, with a sensitivity of $0.996 \mathrm{nA} \mathrm{L} \mathrm{nmol}{ }^{-1}$. This work was the first one to describe such kind of modification on a glassy carbon electrode, which presented high electrocatalytic activity towards Cys determinations. ${ }^{14}$ Kubota and co-workers ${ }^{15}$ also detected Cys by chronoamperometry based on the complexation of copper ions onto multi-walled carbon nanotubes, using a glassy carbon platform modified with poly(4-vinylpiridine). The Cys determinations were made under a constant potential of $0.15 \mathrm{~V}$ ( vs. saturated calomel electrode (SCE)). An LOD of $1.50 \mu \mathrm{mol} \mathrm{L}{ }^{-1}$ was found. ${ }^{15}$

The literature also presents a large number of works involving the determination of Cys by voltammetric techniques. Raoof et al. ${ }^{2}$ detected Cys using a carbon paste electrode modified with ferrocenedicarboxylic acid, reaching an LOD of $0.26 \mu \mathrm{mol} \mathrm{L}^{-1}$ by cyclic voltammetry

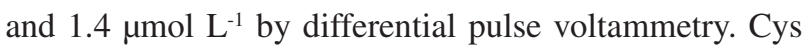
determinations were carried out in pharmaceutical and patient blood plasma samples. ${ }^{2}$ Norouzi and Gorji ${ }^{16}$ modified a carbon paste electrode with cobalt-poly(naphthylamine)/ sodium dodecyl sulfate by electropolymerization. The analytical quantifications of Cys were carried out by cyclic voltammetry and an LOD of $0.80 \mu \mathrm{mol} \mathrm{L} \mathrm{L}^{-1}$ was found. ${ }^{16}$ Cumba et al. ${ }^{12}$ used a graphite paste electrode modified with titanium(IV) and silver hexacyanoferrate composite for Cys determination with an LOD of $3.34 \times 10^{-4} \mathrm{~mol} \mathrm{~L}^{-1} .{ }^{12}$ Although Cys detections were successfully performed using voltammetry, lower LOD values and more sensitive methods were developed using amperometric techniques.

In this context, a wall-jet electrochemical cell emerges as an interesting alternative system for amperometric detections, due to some advantages such as: hydrodynamical properties, fast response, easiness of operation, no mechanically moving parts in the system, reduced waste generation, automatic control, use of low amount of sample and high sampling frequency. ${ }^{17}$ The amperometric detections in the wall-jet cell can be performed with both bare or a modified electrode. It is known that an appropriate modification increases the electrode response and several modification techniques are described in the literature. ${ }^{14,18,19}$ The use of $\mathrm{Cu}$ nanoparticles (CuNP) as electrode modifiers is of great interest for amperometric detections since they can improve the electrode area and enhance conductivity. ${ }^{20}$

The graphite-polyurethane composite electrode (GPUE) was used in this work in the wall-jet system, for the first time. It is prepared from a mixture of graphite and polyurethane obtained from vegetable oil, in 60:40\% (m/m) proportion, respectively. ${ }^{21}$ The use of this electrode has some advantages, such as high hydrophobicity, possibility of modification and resistance to many non-aqueous solvents, wide useful potential window in both acidic and basic media. ${ }^{22}$ Although the GPUE has already been used in flow injection analysis (FIA) determinations, without modification $^{22,23}$ this system has never been applied as a wall-jet detector. In addition, this is the first time that such electrode is modified with electrodeposited CuNP in order to enhance its electrochemical performance.

Thus, this work describes the preparation and application of a homemade wall-jet cell for the amperometric detection of Cys, using a GPUE modified with electrodeposited CuNP (GPUE-CuNP), in an innovative approach that was never described elsewhere. The paper contributes with the innovative exploration of the $\mathrm{Cu}^{0} / \mathrm{Cu}^{+}$-Cys chemistry allied to wall-jet amperometric detection, using the modified GPUE surface with the treated CuNPs.

\section{Experimental}

\section{Reagents and solutions}

All reagents were of analytical grade and used without further purification. Cys (Sigma-Aldrich, St. Louis, USA) standard stock solutions were prepared daily by dissolving appropriate amounts of the amino acid in $0.10 \mathrm{~mol} \mathrm{~L}^{-1}$ phosphate buffer $\mathrm{pH} 7.0$ in order to obtain a $1.0 \times 10^{-2} \mathrm{~mol} \mathrm{~L}^{-1}$ solution. A commercial food supplement containing 100 tablets of $500 \mathrm{mg}$ Cys was purchased from Now Foods ${ }^{\circledR}$ (Los Angeles, USA). According to the Farmacopéia Brasileira (Brazilian pharmacopeia), ${ }^{24}$ $1.0 \times 10^{-2} \mathrm{~mol} \mathrm{~L}^{-1}$ Cys sample stock solutions were prepared with the powder from 20 ground and homogenized tablets of Cys food supplement, dissolved in $0.10 \mathrm{~mol} \mathrm{~L}^{-1}$ phosphate buffer pH 7.0 as well (according to the label contents).

\section{Apparatus}

All the reference or sample solutions were injected manually into the carrier stream using a laboratory 
constructed three-piece injector-commutator made from polymethylmethacrylate (PMMA), ${ }^{25}$ with two fixed side bars and a sliding central one, which is moved for sampling and injection. The solutions were transferred with polyethylene tubing ( $0.8 \mathrm{~mm}$ internal diameter); Fiotubos) and propelled with an IPC 8-channel peristaltic pump (Ismatec).

Scanning electron microscopy (SEM) and energy dispersive X-ray spectroscopy (EDX) measurements were carried out in a LEO 440 (63 kV resolution) operating with a $20 \mathrm{kV}$ electron beam and using an SE1 detector. The GPUE-CuNP electrode sample used was previously prepared with carbon deposition. Micrographs in 25,000 and 50,000x magnifications were acquired at room temperature.

The voltammetric measurements were performed using an Autolab PGSTAT 309 potentiostat/galvanostat (Metrohm) coupled to a microcomputer and controlled by GPES 4.9 software (Metrohm).

Electroactive areas (A) of GPUE and GPUE-CuNP after pre-treatment in $0.010 \mathrm{~mol} \mathrm{~L}^{-1} \mathrm{NaOH}$ were evaluated by chronocoulometry using the integrated form of Cotrell's equation (equation 1 ) in which $n=$ number of electrons $(\mathrm{n}=1), \mathrm{D}_{0}=\mathrm{K}_{3}\left[\mathrm{Fe}(\mathrm{CN})_{6}\right]$ diffusion coefficient in $0.50 \mathrm{~mol} \mathrm{~L}^{-1} \mathrm{KCl}$ in $25^{\circ} \mathrm{C}\left(7.6 \times 10^{-6} \mathrm{~cm}^{2} \mathrm{~s}^{-1}\right),{ }^{26} \mathrm{C}_{0}=$ probe concentration $\left(5.0 \times 10^{-6} \mathrm{~mol} \mathrm{~cm}^{-3}\right), \mathrm{q} \mathrm{t}^{1 / 2}=$ slope obtained with the chronocoulometric curve linearization $\left(\mathrm{C} \mathrm{s}^{1 / 2}\right)$, $\mathrm{F}$ is the Faraday constant $\left(96,485 \mathrm{C} \mathrm{eq}^{-1}\right)$ and $\mathrm{A}$ is the electroactive area. ${ }^{27}$ Chronocoulometric measurements were carried out using an Autolab PGSTAT 204 (Metrohm) coupled to a FRA32M module (Metrohm). Signals were recorded after the application of -0.25 and $0.75 \mathrm{~V}$ ( $v s$. SCE).

$\mathrm{A}=\frac{\mathrm{qt}^{1 / 2} \pi^{1 / 2}}{2 \mathrm{nF} \mathrm{D}_{0}^{1 / 2} \mathrm{C}_{0}}$

Electrochemical impedance spectroscopy (EIS) measurements were also carried out using an Autolab PGSTAT 204 (Metrohm) coupled to FRA32M impedance module (Metrohm) and a microcomputer controlled by NOVA $^{\circledR} 2.1$ software (Metrohm). The measurements for GPUE and GPUE-CuNP were carried out in the presence of $1.0 \mathrm{mmol} \mathrm{L}^{-1} \mathrm{~K}_{3}\left[\mathrm{Fe}(\mathrm{CN})_{6}\right]$, in $0.5 \mathrm{~mol} \mathrm{~L}^{-1} \mathrm{KCl}$, in a frequency range from $1.0 \times 10^{5}$ to $0.10 \mathrm{~Hz}$, with potential amplitude of $0.01 \mathrm{~V}$ and $\mathrm{DC}_{\mathrm{pot}} 0.236 \mathrm{~V}$ (direct current potential, $v s$. SCE) for both electrodes.

The measurements were performed in a three-electrode configuration homemade wall-jet-type flow cell (Figure 2) using the GPUE-CuNP as working electrode. $\mathrm{An} \mathrm{Ag} / \mathrm{AgCl}$, $3.0 \mathrm{~mol} \mathrm{~L}^{-1} \mathrm{KCl}$ was used as reference and a platinum disk (3.0 $\mathrm{mm}$ internal diameter) was the auxiliary electrode.
The body of the electrochemical wall-jet-type flow cell was fabricated with castor oil polyurethane resin (Poliquil, Araraquara, Brazil $)^{28}$ with a net volume of $8.2 \mathrm{~mL}$ discounting the volume of the electrodes introduced into the cell. The cell project was adapted from a detailed fabrication description presented by dos Santos et al. ${ }^{29}$
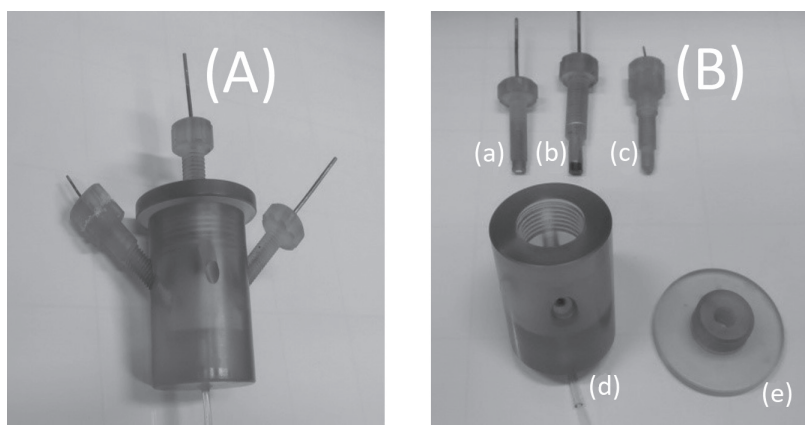

Figure 2. (A) Assembled view of wall-jet cell and (B) exploded view of wall-jet cell with (a) auxiliary, (b) working and (c) reference electrodes, (d) cell body and (e) cover.

Preparation of the modified graphite-polyurethane composite electrode

Preparation and best composition of the GPUE composite electrode was previously established by Mendes et al. ${ }^{21}$ and found to be $60 \%$ graphite and $40 \%$ polyurethane. Briefly, the graphite-polyurethane mixture was homogenized for $5 \mathrm{~min}$ in a glass mortar, pressed in a manual press, extruded as $3.0 \mathrm{~mm}$ diameter rods, and allowed to cure for $24 \mathrm{~h}$ at room temperature, after which the rods were cut into $1.0 \mathrm{~cm}$ sections. The rods were then connected to copper wires with silver epoxy (Electron Microscopy Sciences).

After $24 \mathrm{~h}$, the composite/copper wire assembly was inserted into the screw-type polyurethane support (5.0 $\mathrm{mm}$ diameter, $4.5 \mathrm{~cm}$ length, Figure $2 \mathrm{~B}$, working electrode, b), which was sealed with epoxy resin (Silaex SQ 3024 ) and allowed to cure for $24 \mathrm{~h}$. Mechanical polishing with 500 grit sandpaper was used to remove excess epoxy resin from the surface and expose the modified composite. Finally, the electrode was sonicated in isopropanol for $5 \mathrm{~min}$ and then in water for $5 \mathrm{~min}$ before each working day.

The electrodeposition of CuNP in the renewed surface of the GPUE was made based on the method proposed by $\mathrm{Xi}$ et $a .^{30}$ using cyclic voltammetry with scan rate of $20 \mathrm{mV} \mathrm{s}^{-1}$ in a $5.0 \mathrm{mmol} \mathrm{L}^{-1} \mathrm{CuCl}_{2}$ solution, in a potential range from 0.0 to $-1.5 \mathrm{~V}$ ( $v s$. SCE) in 3 scans. The GPUE-CuNP was subsequently submitted to an electrochemical treatment in $0.010 \mathrm{~mol} \mathrm{~L}^{-1} \mathrm{NaOH}$ in cyclic voltammetry $\left(-1.0\right.$ to $1.0 \mathrm{~V}$ vs. SCE, $v=200 \mathrm{mV} \mathrm{s}^{-1}$, 50 scans), according to the procedure proposed by 
Prabhu and Baldwin. ${ }^{31}$ This treatment was proposed in order to produce $\mathrm{Cu}$ oxides on the electrode surface, ${ }^{32,33}$ which improve the analytical performances in Cys determination, since a well-known interaction between $\mathrm{Cu}^{+}$and $\mathrm{Cys}$ takes place as already described..$^{34}$

\section{Flow injection measurements}

The effect of different parameters regarding the flow system, such as the distance between the working electrode and the injection hole $(0.38,0.75,1.5$ and $1.8 \mathrm{~mm})$, carrier solution flow rate $\left(7.0,10.0\right.$ and $\left.14.0 \mathrm{~mL} \mathrm{~min}^{-1}\right)$, detection potential ( -300 and $-400 \mathrm{~V} v s$. $\mathrm{Ag} / \mathrm{AgCl})$ and sample loop volume (400, 500 and $600 \mu \mathrm{L})$ were evaluated.

Using the optimized conditions an analytical curve was obtained by injection of different concentrations of Cys, in quintuplicate, in increasing concentration order from 30.0 to $130.0 \mu \mathrm{mol} \mathrm{L}-1$. The same procedure was repeated in decreasing concentration order to check if any memory effect was present.

Interference tests were performed using ascorbic acid, tryptophan, piridoxine and sulfate, in quintuplicate in the presence of $70.0 \mu \mathrm{mol} \mathrm{L} \mathrm{L}^{-1} \mathrm{Cys}$ and interferents concentrations of 35.0, 70.0 and $140.0 \mu \mathrm{mol} \mathrm{L}-1$.

For Cys determination in food supplement, each Cys standard solution was injected five times in the following concentrations: 50.0, 70.0, 90.0 and $110.0 \mu \mathrm{mol} \mathrm{L}^{-1}$ in order to obtain a calibration curve. Then, an $80.0 \mu \mathrm{mol} \mathrm{L}^{-1}$ Cys supplement sample (according to the label value) was injected in triplicate.

\section{Comparative method}

A comparative method was performed by high performance liquid chromatography (HPLC) using an 850 IC Professional Cation-HP Gradient ion chromatograph (IC) equipped with an amperometric IC detector, using a gold disk as the working electrode and a palladium reference electrode (Metrohm Pensalab). An ion exchange Dionex ${ }^{\mathrm{TM}}$ CarboPac ${ }^{\mathrm{TM}}$ PA1 column (Thermo Fisher Scientific) based on polystyrene was used for the Cys separation, coupled to a pre-column based on the same material, in order to separate particles and impurities from the analyte. The procedure was adapted from da Silva et al. ${ }^{35}$ previous work.

A gradient system was adopted for the Cys separation, using $0.20 \mathrm{~mol} \mathrm{~L}^{-1} \mathrm{NaOH}$ and $0.40 \mathrm{~mol} \mathrm{~L}^{-1}$ sodium acetate in a 40:60 percent composition (v/v) mobile phase, in the following analysis conditions: column temperature and detector of 35 and $32{ }^{\circ} \mathrm{C}$, respectively, mobile phase flow rate of $1.0 \mathrm{~mL} \mathrm{~min}^{-1}$ and $25.0 \mu \mathrm{L}$ injection volume.

\section{Results and Discussion}

\section{GPUE-CuNP characterization}

After the preparation of the GPUE-CuNP electrode, the morphologies of the electrodeposited CuNP were analyzed by SEM after pre-treatment in basic medium. Figures $3 \mathrm{a}$ and $3 \mathrm{~b}$ present the obtained micrographs in 25,000 and $50,000 \times$.

These images also revealed an homogeneous recovering of the entire electrode surface by spherical CuNP, with an average diameter of $(93 \pm 16) \mathrm{nm}$. When compared to the CuNP obtained by Xi et al., ${ }^{30}$ the particles obtained here were larger than the ones formed by the mentioned authors. Whilst those authors deposition was carried out in a graphene oxide (GO)/chitosan surface stabilized by $-\mathrm{COO}^{-}$and $-\mathrm{NH}_{3}{ }^{+}$groups, in the present work the deposition at a bare composite surface apparently did not stabilize the NPs in a similar extension and therefore agglomerates could be found. Furthermore, in both SEM images it is noticeable the presence of some cubic particles larger than the CuNP electrodeposited with an average edge length of $(321 \pm 39) \mathrm{nm}$ not described by Xi et al. ${ }^{30}$ This could confirm the presence of a second solid phase, of copper oxides, considering the semi-quantitative EDX data (Figure 3d).

Sequentially, EDX analyses were used to confirm the composition of the deposit observed in SEM analyses. Figures $3 c$ and $3 d$ present EDX spectra obtained at the spherical CuNP and cubic particles, respectively. The spherical NPs have an element percentage of $66 \% \mathrm{C}, 11 \% \mathrm{O}$ and $23 \% \mathrm{Cu}$, while the cubic particles present an element content of $78 \% \mathrm{C}, 9 \% \mathrm{O}$ and $12 \% \mathrm{Cu}$. The high content of carbon element is due to the graphite present in the GPUE composite and sample preparation procedure involving carbon deposition. It is observed that the spherical NPs have twice the $\mathrm{Cu}$ content in comparison with the cubic particles while the $\mathrm{O}$ content in both cases can be considered similar. Although these data are barely semi-quantitative, it could indicate the formation of copper oxide particles and a remaining metallic copper portion. Accordingly, since different studies in the literature propose the formation of $\mathrm{Cu}_{2} \mathrm{O}$ and $\mathrm{CuO}$ species after submitting a $\mathrm{Cu}$ surface to $\mathrm{NaOH},{ }^{20,31,33,36}$ it is inferred that these species are also formed during the $\mathrm{NaOH}$ electrochemical pretreatment of the GPUE-CuNP.

\section{GPUE-CuNP electrochemical characterization}

Initially, the electroactive areas of GPUE and GPUE-CuNP after pre-treatment in $0.010 \mathrm{~mol} \mathrm{~L}^{-1} \mathrm{NaOH}$ 

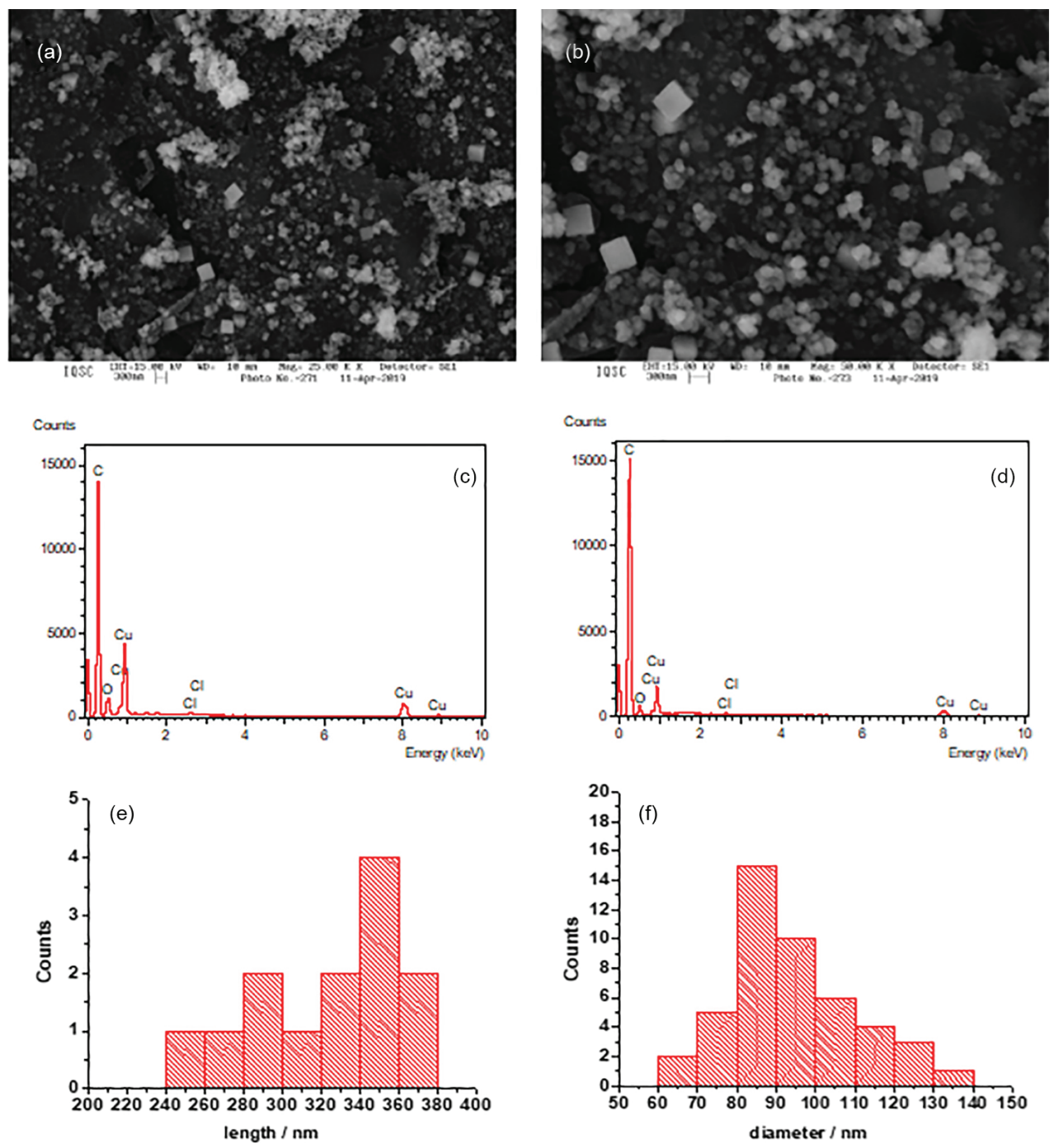

Figure 3. SEM micrographs of the GPUE-CuNP surface obtained in (a) $25.000 \times$ and (b) $50.000 \times$ magnifications. EDX spectra obtained for the (c) spherical particles and (d) cubic particles onto the GPUE-CuNP surface; (e) histogram distribution of size for cubic particles and (f) histogram distribution for spherical particles.

were evaluated by chronocoulometry using the integrated form of Cotrell's equation (equation 1). ${ }^{27}$ Areas of 0.053 and $0.062 \mathrm{~cm}^{2}$ were found for GPUE and GPUE-CuNP, respectively $(n=1)$. The increase in electroactive area with the CuNP modification might be due to formation of new active sites on the electrode surface by the electrodeposition of a conductive material, represented by the remaining $\mathrm{Cu}^{0}$, which could also improve surface roughness.

Then, EIS measurements were carried out in order to verify the conductive behavior regarding the GPUE-CuNP surface in comparison to the unmodified GPUE. The resulting Nyquist plots are presented in Figure 4.

The Nyquist plots for both electrodes present an incomplete semicircle, whose diameter is related to the charge transfer resistance $\left(\mathrm{R}_{\mathrm{ct}}\right)$ onto the electrodes surfaces. The linear portion concerns the Warburg impedance (W), related to diffusional mass processes. ${ }^{37}$ The $R_{c t}$ values

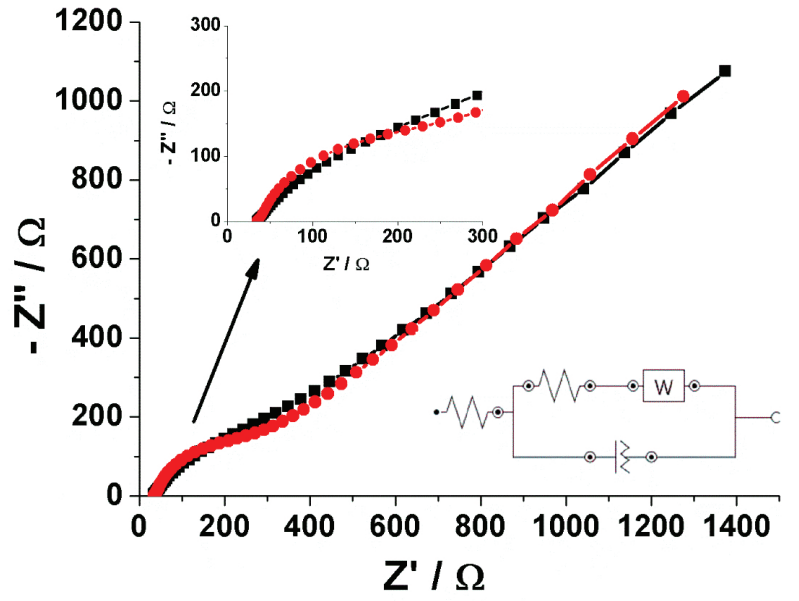

Figure 4. Nyquist plots for GPUE $(\bullet)$ and GPUE-CuNP $(\boldsymbol{\square})$ obtained in the presence of $1.0 \mathrm{mmol} \mathrm{L}^{-1} \mathrm{~K}_{3}\left[\mathrm{Fe}(\mathrm{CN})_{6}\right]$, in $0.5 \mathrm{~mol} \mathrm{~L}^{-1} \mathrm{KCl}$, in a frequency range from $1.0 \times 10^{5}$ to $0.10 \mathrm{~Hz}$, with potential amplitude of $0.01 \mathrm{~V}$ and $\mathrm{DC}_{\mathrm{pot}}$ of $0.236 \mathrm{~V}$ for both electrodes. Inset: Randles electric circuit model fitted for GPUE-CuNP based on EIS measurements. 
obtained for GPUE and GPUE-CuNP were 278 and $483 \Omega$, respectively. It is noticeable that $R_{c t}$ increases after the electrodeposition of CuNP followed by pre-treatment in $\mathrm{NaOH}$ due to the formation of non-conductive copper oxides. It was also observed that diffusional mass control takes place in higher frequencies. In addition, there is a constant phase element (CPE) instead of a simple double-layer capacitance $\left(\mathrm{C}_{\mathrm{d}}\right)$, attributed to the electrode surface roughness. ${ }^{37}$ Therefore, it was possible to fit the observed behavior to an electric circuit model, presented in the inset of Figure 4.

Thus, although the GPUE-CuNP presented higher $\mathrm{R}_{\mathrm{ct}}$ values in comparison to the bare GPUE, it was proposed as a working electrode for the further studies involving Cys determinations, based on several reports in the literature concerning chemical interactions between Cys and copper ions generated in such kind of electrode modification..$^{32,33,38}$

\section{Cysteine redox behavior at GPUE and GPUE-CuNP}

The voltammetric response of Cys at bare GPUE by cyclic voltammetry, from -1.2 to $1.0 \mathrm{~V}$ ( $v \mathrm{~s}$. SCE), $v=50 \mathrm{mV} \mathrm{s}^{-1}$ in $1.0 \mathrm{mmol} \mathrm{L}^{-1}$ concentration in $0.10 \mathrm{~mol} \mathrm{~L}^{-1}$ phosphate buffer $\mathrm{pH} 7.0$ was first evaluated. It was noticeable that there is no voltammetric response of Cys at the bare GPUE (Figure 5). The wave at ca. $-0.5 \mathrm{~V}$ (vs. SCE) was attributed to phosphate ions ${ }^{39}$ and is considered out of the chosen analytical potential window.

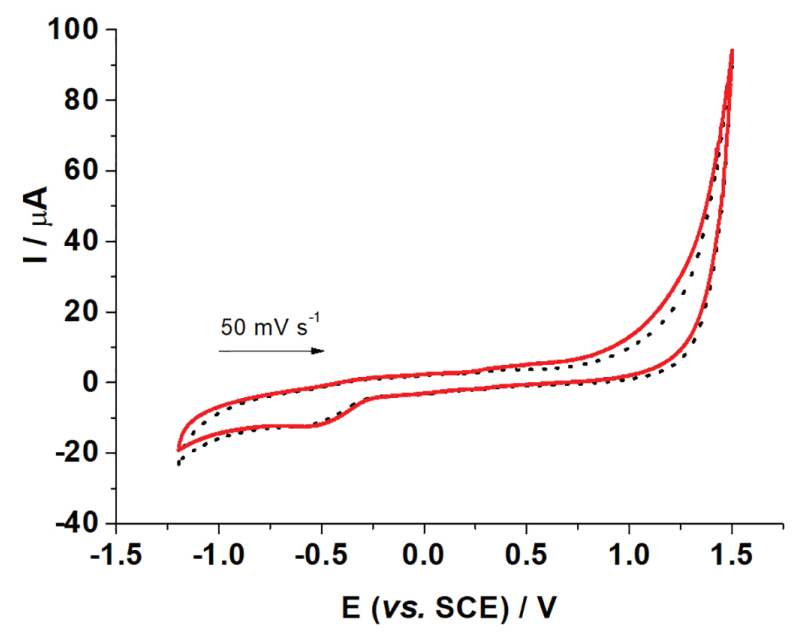

Figure 5. Cyclic voltammograms obtained with the bare GPUE in the presence of $1.0 \mathrm{mmol} \mathrm{L}^{-1}$ Cys in $0.10 \mathrm{~mol} \mathrm{~L}^{-1}$ phosphate buffer $\mathrm{pH} 7.0$ : Cys (solid red line) and blank (black dotted line). $v=50 \mathrm{mV} \mathrm{s}^{-1}$.

Thus it was decided to promote a modification on the electrode surface by electrodepositing CuNP, since the interaction between this metal and Cys is known and largely studied in the literature. ${ }^{34,38,40,41}$ After CuNP electrodeposition, cyclic voltammograms obtained in the presence of $1.0 \mathrm{mmol} \mathrm{L}^{-1}$ Cys in $0.10 \mathrm{~mol} \mathrm{~L}^{-1}$ phosphate buffer $\mathrm{pH} 7.0$ demonstrated that although copper oxidation and reduction took place, no significant changes in current intensities were observed. Furthermore, an additional treatment in basic media of the modified electrode was proposed in order to generate a mixture of active copper oxide sites on the metallic layer. ${ }^{31,42}$ The resulting deposit presented a red color, suggesting that $\mathrm{Cu}_{2} \mathrm{O}$ was mainly formed. ${ }^{33}$

Sequentially, cyclic voltammograms were recorded from -1.5 to $1.0 \mathrm{~V}$ (vs. SCE) using a $0.10 \mathrm{~mol} \mathrm{~L}^{-1}$ phosphate buffer $\mathrm{pH} 7.0$ solution in the absence of Cys to evaluate the voltammetric profile of GPUE-CuNP after electrochemical cycling in $0.010 \mathrm{~mol} \mathrm{~L}^{-1} \mathrm{NaOH}$, as presented in Figure 6.



Figure 6. Cyclic voltammogram obtained with treated GPUE-CuNP, in $0.10 \mathrm{~mol} \mathrm{~L}^{-1}$ phosphate buffer $\mathrm{pH} 7.0$ with $v=50 \mathrm{mV} \mathrm{s}^{-1}$.

An oxidation peak was observed in approximately $-0.07 \mathrm{~V}$ ( vs. SCE, Figure 6a), attributed to the oxidation of remaining $\mathrm{Cu}^{0}$ after treatment to $\mathrm{Cu}^{+}$leading to $\mathrm{Cu}(\mathrm{OH})$ species $^{32,43}$ as represented in equation 2. It is also known that $\mathrm{Cu}(\mathrm{OH})$ exists in equilibrium with $\mathrm{Cu}_{2} \mathrm{O}$, according to equation $3 .^{33}$

$\mathrm{Cu}^{0}+\mathrm{OH}^{-} \rightleftharpoons \mathrm{Cu}(\mathrm{OH})+\mathrm{e}^{-}$

$2 \mathrm{CuOH} \rightleftharpoons \mathrm{Cu}_{2} \mathrm{O}+\mathrm{H}_{2} \mathrm{O}$

In the cathodic direction, a reduction peak in $-0.25 \mathrm{~V}$ (vs. SCE, Figure 6b) was observed, regarding the $\mathrm{Cu}^{+}$ions reduction to $\mathrm{Cu}^{0} .^{32,43}$ According to Kano et al. , $^{33}$ the current intensity of this peak is more intense than that observed in the anodic sweep, due to the presence of dissolved oxygen in neutral and acidic solutions. ${ }^{33}$

Another reduction peak appeared at even more negative potential $(-1.25 \mathrm{~V} v s$. SCE, Figure $6 \mathrm{c})$, possibly related to the direct reduction of copper oxides (in this case, $\mathrm{Cu}(\mathrm{OH})_{2}$ or $\mathrm{CuO}$ ) to $\mathrm{Cu}^{0}$, since oxygen was not removed from 
solution. ${ }^{32,33}$ In order to avoid such event, that could affect the desired oxides in electrodeposited/treated copper film on GPUE-CuNP surface, the potential interval for further analytical studies was defined as -1.00 to $0.50 \mathrm{~V}$ ( $v s$. SCE).

Palmer ${ }^{44}$ discussed the solubility of copper oxides in aqueous media regarding its dependence on $\mathrm{pH}$ and temperature. At $25^{\circ} \mathrm{C}$, the solubility of $\mathrm{Cu}_{2} \mathrm{O}$ reaches its maximum in $\mathrm{pH}$ values between 8 and 10, approximately. Despite $\mathrm{Cu}_{2} \mathrm{O}$ presenting a certain degree of solubility in $\mathrm{pH} 7.0$, it was assumed that the application of the GPUE-CuNP with such oxide in neutral media would not affect the electrode stability in a distinguished extension. On the other hand, it is known that the second Cys ionization $\mathrm{p} K_{\mathrm{a}}\left(\mathrm{p} K_{\mathrm{a} 2}\right)$ is about $8.0,{ }^{4}$ from which it can increasingly found as deprotonated ${ }^{-} \mathrm{S}-\mathrm{R}$ form. However, due to $\mathrm{Cu}_{2} \mathrm{O}$ dissolution, the use of $\mathrm{pH} 8.0$ aiming the formation of deprotonated Cys is not adequate and the $\mathrm{pH} 7.0$ becomes the more viable $\mathrm{pH}$ for the supporting electrolyte in this case. Therefore, the use of neutral media in our study is likely to favor the interaction between $\mathrm{Cu}^{+}$ions and $-\mathrm{S}-\mathrm{R}$ and is of great importance aiming Cys determinations in biological samples in physiological $\mathrm{pH}$ (7.4).

In sequence, the effect of Cys concentration in its electrochemical response was evaluated using GPUE-CuNP by cyclic voltammetry, from -1.0 to $0.5 \mathrm{~V}$ ( $v s$. SCE), $v=50 \mathrm{mV} \mathrm{s}^{-1}$ in a 20.0 up to $100 \mu \mathrm{mol} \mathrm{L}^{-1}$ Cys solution prepared in $0.10 \mathrm{~mol} \mathrm{~L}^{-1}$ phosphate buffer $\mathrm{pH}$ 7.0. The resulting voltammograms are presented in Figure 7.

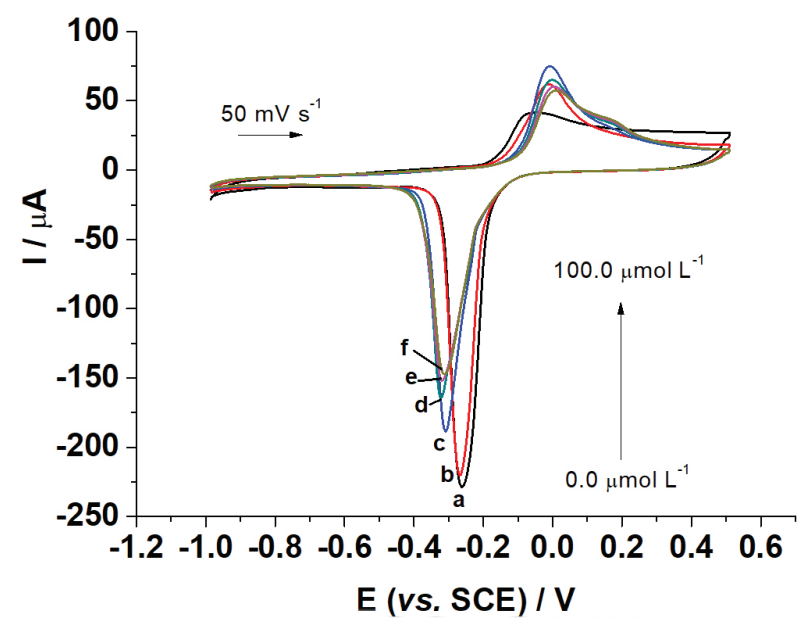

Figure 7. Cyclic voltammograms using the treated GPUE-CuNP in $0.10 \mathrm{~mol} \mathrm{~L}^{-1}$ phosphate buffer $\mathrm{pH} 7.0$ varying Cys concentration from (a) 0 ; (b) 20.0 ; (c) 40.0 ; (d) 60.0 ; (e) 80.0 and (f) $100.0 \mu \mathrm{mol} \mathrm{L}^{-1} \cdot v=50 \mathrm{mV} \mathrm{s}^{-1}$.

In the first addition of Cys to the solution a shift of $\mathrm{Cu}^{0} / \mathrm{Cu}^{+}$oxidation peak to more positive potentials was observed with a slight increase in current intensity at GPUE-CuNP due to the presence of Cys. Similar phenomenon occurred in the reduction peak, while it was displaced to more negative potentials. This might be related to the Cys interaction with $\mathrm{Cu}^{+}$ions ${ }^{34,40}$ onto the treated GPUE-CuNP surface, due to the formation of a stable and soluble $\mathrm{Cys}-\mathrm{Cu}^{+}$complex. This phenomenon has already been described in the literature ${ }^{34,38,40}$ and should occur according to equation 4: its occurrence is corroborated by the displacement of the reduction peak towards more negative potentials. The high stability of $\mathrm{Cys}-\mathrm{Cu}^{+}$complex provides a high value for the equilibrium constant to the complex formation in equation 4 favoring the products.

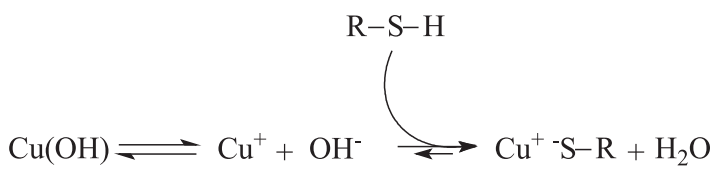

Moreover, it is observed that as Cys concentration increases, the current intensity of the oxidation peak intensity at ca. $0.0 \mathrm{~V}(v s . \mathrm{SCE})$ stabilized in approximately constant values while the reduction peak presented a clear decreasing in its current intensity. These events might be caused by a consumption of $\mathrm{Cu}^{+}$ions due to the $\mathrm{Cys}-\mathrm{Cu}^{+}$formation, onto the GPUE-CuNP surface. Consequently, the availability of $\mathrm{Cu}^{+}$species to be reduced in the cathodic sweep decreases and a lowering in current intensity of the reduction peak proportional to the Cys concentration is observed. Such decrease can be explored for analytical purposes.

Flow injection parameters evaluation and analytical curve in wall-jet system

Once defined the electrode surface and evaluated the possible electrodic reaction between Cys and CuNP, the treated GPUE-CuNP performance as an amperometric detector in flow analysis was evaluated using the wall-jet system.

The effect of the distance between the working electrode and the injection hole was the first parameter to be evaluated. The distance values were $0.38,0.75,1.5$ and $1.8 \mathrm{~mm}$, defined by the electrode screw-pass in the bottom of the cell. Successive injections of $0.20 \mathrm{mmol} \mathrm{L}^{-1}$ Cys solution in $0.10 \mathrm{~mol} \mathrm{~L}^{-1}$ phosphate buffer $\mathrm{pH} 7.0$ were performed. The current values and the standard deviations were $59 \pm 5,61 \pm 5,82 \pm 7$ and $78 \pm 8 \mu \mathrm{A}$, respectively. Thus, the distance of $1.5 \mathrm{~mm}$ was chosen since it presented a higher current and slightly lower deviation.

The effect of -0.3 and $-0.4 \mathrm{~V}$ ( $v s . \mathrm{Ag} / \mathrm{AgCl}$ ) as the detection potential was evaluated, by successive injections of $0.20 \mathrm{mmol} \mathrm{L}^{-1} \mathrm{Cys}$ solution in the same medium. In these potentials, the $\mathrm{Cu}^{+}-\mathrm{Cys}$ complex is already presented in its reduced form (Figure 6), which permits $\mathrm{Cu}^{+}$reduction to $\mathrm{Cu}^{0}$ in the presence of Cys during the amperometric 
detection in the wall-jet system. Better response was achieved using $-0.3 \mathrm{~V}$ ( $v s$. $\mathrm{Ag} / \mathrm{AgCl}$ ), since at $-0.4 \mathrm{~V}$ (vs. $\mathrm{Ag} / \mathrm{AgCl})$ no amperometric response was observed.

Next, the effect of the carrier solution flow rate was evaluated, varying it between 7.0, 10.0 and $14.0 \mathrm{~mL} \mathrm{~min}^{-1}$, with successive injections of $0.20 \mathrm{mmol} \mathrm{L}^{-1} \mathrm{Cys}$ solution in $0.10 \mathrm{~mol} \mathrm{~L}^{-1}$ phosphate buffer $\mathrm{pH} 7.0$, under the optimized detection potential $(-0.3 \mathrm{~V} v$ s. $\mathrm{Ag} / \mathrm{AgCl})$. According to the results, a flow rate of $10.0 \mathrm{~mL} \mathrm{~min}^{-1}$ was chosen for further studies since it presented higher current intensity.

The effect of the sample loop volume in the transient signals was also investigated, from 400 to $600 \mu \mathrm{L}$ by successive injections of $0.20 \mathrm{mmol} \mathrm{L}^{-1}$ Cys solution in $0.10 \mathrm{~mol} \mathrm{~L}^{-1}$ phosphate buffer, $\mathrm{pH} 7.0$, under a constant flow rate of $10 \mathrm{~mL} \mathrm{~min}^{-1}$ and amperometric detection at $-0.3 \mathrm{~V}$ (vs. Ag/AgCl). Although the lowest current signal change was found using $600 \mu \mathrm{L}$, it presented smaller standard deviation on the successive injections than 400 and $500 \mu \mathrm{L}$. Hence, it was chosen as the optimized sample loop volume for the further analytical experiments.

In sequence, an analytical curve was obtained between 30.0 and $130.0 \mu \mathrm{mol} \mathrm{L}^{-1}$ Cys concentrations in order to evaluate the behavior of the amperometric response of the treated GPUE-CuNP in increasing concentrations of Cys. The resulting transient signal is presented in Figure 8.

Under the optimized conditions, a linear response was obtained in the entire studied interval, of 30.0 and $130.0 \mu \mathrm{mol} \mathrm{L}{ }^{-1}$ Cys concentrations range (Figure 8 inset), described by equation 5 , in which $\mathrm{I}_{\mathrm{p}}$ is the peak current.

$\mathrm{I}_{\mathrm{p}}=33.6 \times 10^{-6} \mathrm{~A}-0.13 \mathrm{C}_{\mathrm{Cys}} \mathrm{A} \mu \mathrm{mol}^{-1} \mathrm{~L}$

The LOD obtained in this interval was of $4.24 \mu \mathrm{mol} \mathrm{L}^{-1}$, determined according to Long and Winefordner, ${ }^{45}$ considering the ratio between $3 \mathrm{~S}_{\mathrm{DA}}$ (analytical blank standard deviation, obtained from the linear range described

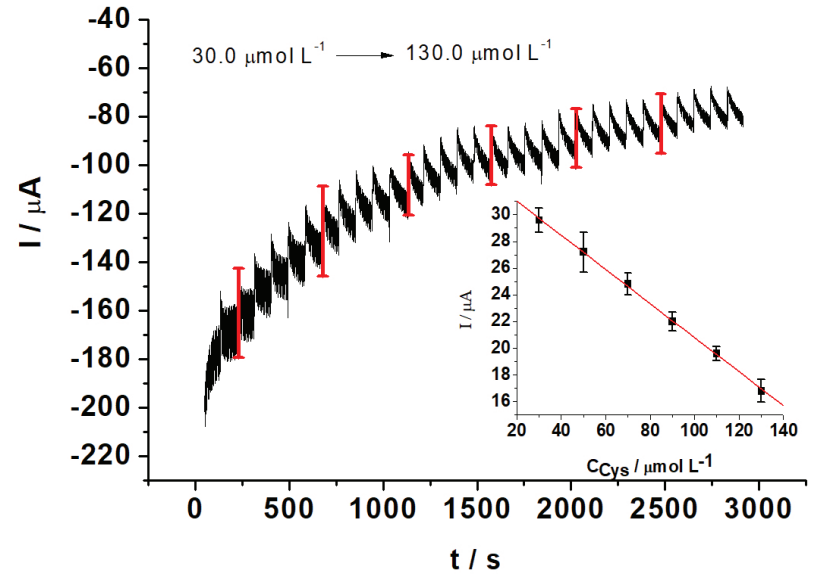

Figure 8. Transient signals obtained at the composite GPUE-CuNP using concentrations between 30.0 and $130.0 \mu \mathrm{mol} \mathrm{L}^{-1}$ Cys in $0.10 \mathrm{~mol} \mathrm{~L}^{-1}$ phosphate buffer $\mathrm{pH} 7.0$ as a carrier, in the previously optimized parameters. Inset: analytical curve.

above) and the slope of equation 5. An analytical frequency of 36 determinations per hour was obtained.

Figure 8 presents transient signals obtained with the proposed system. The bars represent how the current was sampled in this curve and was used for the measurement of transient signals obtained in all wall-jet procedures. In addition, a baseline deviation observed during the analysis was attributed to a continuous change in the electrode surface due to dissolution of the copper oxides as $\mathrm{Cu}^{+-} \mathrm{S}-\mathrm{R}$ complex is formed. Such baseline deviation occurred in all experiments with the GPUE-CuNP. According to Prabhu and Baldwin, ${ }^{31}$ who worked with copper ultra-microelectrodes, in order to have an appropriate electrode performance it is necessary to establish an appropriate balance of copper oxides and metallic copper on the electrode surface. It seems that the presence of Cys promotes changes in this balance as presented by the baseline change.

Table 1 presents a comparison between several flowinjection methods for Cys determination, with different

Table 1. Comparison of different flow-injection based methods for Cys determination in the literature

\begin{tabular}{|c|c|c|c|c|}
\hline Detection & Method & $\mathrm{LOD} /(\mu \mathrm{mol} \mathrm{L}-1)$ & $\begin{array}{c}\text { Sampling } \\
\text { frequency } / \mathrm{h}^{-1}\end{array}$ & Reference \\
\hline Colorimetry & $\begin{array}{l}\text { complexation of } \mathrm{Cu}^{2+} \text { with } \\
5,10,15,20 \text {-tetrakis }(4-N \text {-trimethylamino- } \\
\text { phenyl) porphyrin }\end{array}$ & 0.124 & 0.33 & 46 \\
\hline Chemiluminescence & luminol-persulfate emission & 0.0005 & 120 & 47 \\
\hline Voltammetry & $\begin{array}{l}\text { chemisorption reaction on polycrystalline } \\
\text { gold electrode }\end{array}$ & 0.50 & 23 & 48 \\
\hline Spectrophotometry & $\begin{array}{l}\text { complexation with ammonium } \\
18 \text {-molybdophosphate }\end{array}$ & 3.0 & 240 & 7 \\
\hline Spectrophotometry & reaction with 18 molybdo-2-phosphate anion & 3.0 & 20 & 49 \\
\hline Amperometry & $\begin{array}{l}\text { in situ complexation with } \mathrm{Cu}^{+} \text {ions onto } \\
\text { GPUE-CuNP }\end{array}$ & 4.24 & 36 & this work \\
\hline
\end{tabular}

LOD: limit of detection; GPUE-CuNP: graphite-polyurethane composite electrode modified by electrodeposition of copper nanoparticles. 
detection techniques. Despite the relatively larger LOD compared to other procedures in Table 1, the present method has an advantageous analytical frequency. The device can be prepared without need of sophisticated and/or expensive reagents nor tedious derivatization reactions associated with relatively low reagent consumption and waste generation. The modified electrode is robust, easy to operate and with relatively low assembling cost.

Interference tests, comparative method and determination of Cys in food supplement

Interference tests were carried out to evaluate the possibility of an electrochemical interference in Cys response using GPUE-CuNP. The compounds evaluated were ascorbic acid, tryptophan, pyridoxine and sulfate. Interferents were added to $70.0 \mu \mathrm{mol} \mathrm{L}^{-1}$ Cys standard solutions so that their concentrations were 35.0, 70.0 and $140.0 \mu \mathrm{mol} \mathrm{L}{ }^{-1}$.

The analyses were performed in quintuplicate in the walljet system at GPUE-CuNP as the amperometric detector in the sequence $70.0 \mu \mathrm{mol} \mathrm{L}{ }^{-1} \mathrm{Cys} \rightarrow \mathrm{Cys}+35.0 \mu \mathrm{mol} \mathrm{L}-1$ interferent $\rightarrow$ Cys $+70.0 \mu$ mol L-1 interferent $\rightarrow$ Cys + $140.0 \mu \mathrm{mol} \mathrm{L}{ }^{-1}$ interferent $\rightarrow 70.0 \mu \mathrm{mol} \mathrm{L}{ }^{-1}$ Cys. The interference percentage found for each compound analyzed is presented in Table 2 .

From data in Table 2, sulfate ion presented the lowest interference in the system since it does not complex $\mathrm{Cu}^{+}$ nor affects the redox system. Interference of pyridoxine and tryptophan can be explained according to proposed mechanism, in which Cys reacts with electrodeposited $\mathrm{Cu}^{+}$ ions at GPUE-CuNP, forming the $\mathrm{Cu}^{+-} \mathrm{S}-\mathrm{R}$ complex. The presence of these two interferents in the reactive medium alters the redox equilibrium established between $\mathrm{Cu}^{+}$and Cys since they can also react with $\mathrm{Cu}^{+}$. Consequently, there is a significant change in the transient signal baseline and in the electrode response. Therefore, the remarkably high interference percentage observed when Cys and interferent are added in the same proportion can be explained by $\mathrm{Cu}^{+}$ consumption in stoichiometric quantities, affecting the $\mathrm{Cu}^{+} \mathrm{S}-\mathrm{R}$ complex formation. Ascorbic acid also interferes by reducing $\mathrm{Cu}^{+}$to $\mathrm{Cu}^{0}$, as represented by the noticeable decrease in copper signal, making it the most severe interferent. Although not desirable, these interferences corroborate the proposed complexation mechanism involving the treated CuNP and Cys.

The data in Table 2 revealed that the peak current in the first line varies significantly for all interferants after each new surface is prepared, implying in a relatively poor intraday reproducibility, $\mathrm{I}_{\mathrm{p}}=6 \pm 3 \mu \mathrm{A}(\mathrm{n}=8$ electrodepositions, 5 replicates each), for $70 \mu \mathrm{mol} \mathrm{L}-1$ Cys in $0.10 \mathrm{~mol} \mathrm{~L}^{-1}$
Table 2. Interference percentage observed using GPUE-CuNP for Cys amperometric detection in wall-jet system

\begin{tabular}{|c|c|c|c|}
\hline Interferent & Injection / $\left(\mu \mathrm{mol} \mathrm{L} \mathrm{L}^{-1}\right)$ & $\mathrm{I}_{\mathrm{p}} / \mu \mathrm{A}$ & $\begin{array}{c}\text { Interference / } \\
\%\end{array}$ \\
\hline \multirow{5}{*}{$\mathrm{SO}_{4}^{2-}$} & 70.0 Cys & $4.2 \pm 0.2$ & - \\
\hline & $70.0 \mathrm{Cys}+35.0 \mathrm{SO}_{4}{ }^{2-}$ & $4.2 \pm 0.3$ & +0.43 \\
\hline & $70.0 \mathrm{Cys}+70.0 \mathrm{SO}_{4}{ }^{2-}$ & $1.45 \pm 0.01$ & -66.0 \\
\hline & $70.0 \mathrm{Cys}+140.0 \mathrm{SO}_{4}{ }^{2-}$ & $4.2 \pm 0.4$ & +0.14 \\
\hline & 70.0 Cys & $3.4 \pm 0.4$ & -19.0 \\
\hline \multirow{5}{*}{$\begin{array}{l}\text { Pyridoxine } \\
\text { (B6) }\end{array}$} & 70.0 Cys & $2.0 \pm 0.3$ & - \\
\hline & 70.0 Cys + 35.0 B6 & $1.7 \pm 0.1$ & -12.7 \\
\hline & 70.0 Cys + 70.0 B6 & $0.86 \pm 0.03$ & -55.7 \\
\hline & 70.0 Cys + 140.0 B6 & $1.0 \pm 0.1$ & -47.0 \\
\hline & 70.0 Cys & $0.9 \pm 0.1$ & -50.6 \\
\hline \multirow{5}{*}{$\begin{array}{l}\text { Tryptophan } \\
\text { (Trp) }\end{array}$} & 70.0 Cys & $12 \pm 2$ & - \\
\hline & 70.0 Cys + 35.0 Trp & $9.5 \pm 0.6$ & -18.3 \\
\hline & 70.0 Cys + 70.0 Trp & $3.0 \pm 0.6$ & -74.0 \\
\hline & 70.0 Cys + 140.0 Trp & $6.0 \pm 0.6$ & -48.5 \\
\hline & 70.0 Cys & $5.0 \pm 0.1$ & -57.0 \\
\hline \multirow{5}{*}{$\begin{array}{l}\text { Ascorbic Acid } \\
\text { (AA) }\end{array}$} & 70.0 Cys & $21 \pm 2$ & - \\
\hline & $70.0 \mathrm{Cys}+35.0 \mathrm{AA}$ & $12 \pm 0.7$ & -44.4 \\
\hline & $70.0 \mathrm{Cys}+70.0 \mathrm{AA}$ & $9 \pm 1$ & -57.1 \\
\hline & 70.0 Cys + 140.0 AA & $6.9 \pm 0.7$ & -67.3 \\
\hline & 70.0 Cys & $4.7 \pm 0.5$ & -77.8 \\
\hline
\end{tabular}

$\mathrm{I}_{\mathrm{p}}$ : peak current; Cys: cysteine.

phosphate buffer $\mathrm{pH} 7.0$ at $-0.3 \mathrm{~V}(v s . \mathrm{Ag} / \mathrm{AgCl})$. Using cyclic voltammetry, for 5 different electrodepositions, the average current for $40 \mu \mathrm{mol} \mathrm{L}-1$ Cys in $0.10 \mathrm{~mol} \mathrm{~L}^{-1}$ phosphate buffer $\mathrm{pH} 7.0$ was $160 \pm 27 \mu \mathrm{A}$. However, it is important to note that although the intra-day reproducibility is relatively poor the repeatability in the same set of measurements at the same surface is acceptable, as presented by data in Table 2 .

The applicability of the GPUE-CuNP in the walljet system as a FIA amperometric detector for the determination of Cys was evaluated analyzing a commercial food supplement containing $500 \mathrm{mg}$ of Cys. Standard solutions were prepared by appropriate dilutions in order to obtain 50.0, 70.0, 90.0 and $110.0 \mu \mathrm{mol} \mathrm{L}^{-1}$ Cys standard solutions. A sample solution of $80.0 \mu \mathrm{mol} \mathrm{L}^{-1}$ (according to the label value) was prepared similarly. A linear behavior was observed, except for the $110.0 \mu \mathrm{mol} \mathrm{L} \mathrm{L}^{-1} \mathrm{Cys}$, as represented by equation 6 .

$\mathrm{I}_{\mathrm{p}}=-8.49 \times 10^{-6} \mathrm{~A}+0.215 \mathrm{C}_{\mathrm{Cys}} \mathrm{A} \mu \mathrm{mol}^{-1} \mathrm{~L}$; $\mathrm{R}=0.998$

From this study, a sample concentration of $86.5 \mu \mathrm{mol} \mathrm{L}^{-1}$ of Cys in the food supplement was recovered, equivalent to $541 \mathrm{mg}$ of Cys per tablet. 
The Cys determination in food supplements was also performed by HPLC using an ion-exchange column based on polystyrene, according to the Brazilian pharmacopeia ${ }^{24}$ in order to evaluate the performance of the proposed walljet system. An $80.0 \mu \mathrm{mol} \mathrm{L}^{-1}$ sample and standard solution were prepared by appropriate dilutions to obtain 30.0, 50.0, 70.0 and $90.0 \mu \mathrm{mol} \mathrm{L}^{-1}$ in Cys. In this study, the standard addition method was chosen. The Cys contents obtained for wall-jet and HPLC were, respectively, $(541 \pm 32)$ and $(516 \pm 11) \mathrm{mg}$. The theoretical and experimental Cys values found were in agreement with Student's $t$-test for a 95\% confidence level (Table 3).

Table 3. Comparison between the wall-jet system with a GPUE-CuNP as the amperometric detector and HPLC

\begin{tabular}{lccccc}
\hline Sample & \multicolumn{3}{c}{ Cys / mg } & \multirow{2}{*}{$\mathrm{E}_{1} / \%$} & $\mathrm{E}_{2} / \%$ \\
\cline { 2 - 4 } & Labeled & Wall-jet & HPLC & & \\
\hline Now Foods $^{\circledast}$ & 500 & $541 \pm 32$ & $516 \pm 11$ & 4.8 & 8.2 \\
\hline
\end{tabular}

Cys: cysteine; HPLC: high performance liquid chromatography; $\mathrm{E}_{1}$ : wall-jet $v s . \mathrm{HPLC}=($ wall-jet $-\mathrm{HPLC} / \mathrm{HPLC}) \times 100 ; \mathrm{E}_{2}$ : wall-jet $v s$. labeled $=($ wall-jet - labeled/labeled $) \times 100$.

\section{Conclusions}

A graphite-polyurethane composite electrode was modified with CuNP by electrodeposition. In order to improve the GPUE-CuNP electrochemical response to Cys, an electrochemical pretreatment in $\mathrm{NaOH}$ was performed, resulting on $\mathrm{Cu}^{+}$oxides on the electrode surface. According to voltammetric data, an interaction between $\mathrm{Cys}$ and $\mathrm{Cu}^{+}$at GPUE-CuNP, forming the complex $\mathrm{Cu}^{+} \mathrm{S}-\mathrm{R}$ was proposed based on well-known phenomena and largely discussed in the literature.

The GPUE-CuNP was submitted to Cys determination using a wall-jet system, with LOD of $4.24 \mu \mathrm{mol} \mathrm{L} \mathrm{L}^{-1}$. The system was used for the determination of Cys in food supplements with results comparable with HPLC procedure without interference from the concomitants in the supplement formulation.

Interference tests carried out with $\mathrm{SO}_{4}{ }^{2-}$, a weak complexing agent, did not interfere significantly in Cys determination, while pyridoxine and tryptophan seemed to complex with $\mathrm{Cu}^{+}$leading to signal decrease. Ascorbic acid also interfered probably due to reduction of $\mathrm{Cu}^{+}$. These effects corroborate the proposed complexation mechanism.

The proposed system has proved itself as an interesting alternative for Cys determinations in quality control of food supplement samples, with low-cost, sensibility, easiness of operation, no need of sample derivatization and an appropriate selectivity and sensitivity for such kind of samples.

\section{Acknowledgments}

Authors wish to thank FAPESP (grants 2018/11071-0 and 2017/04211-7), Coordenação de Aperfeiçoamento de Pessoal de Nível Superior (Capes, Financial Code 001) and CNPq. The authors are also grateful to Prof Dr Nelson Ramos Stradiotto and Dr José Luiz da Silva (IPBEN, UNESP, Araraquara, Brazil) for the HPLC analyses.

\section{References}

1. Tseng, K. S.; Chen, L. C.; Ho, K. C.; Electroanalysis 2006, 18, 1306.

2. Raoof, J. B.; Ojani, R.; Beitollahi, H.; Electroanalysis 2007, 19, 1822.

3. Ensafi, A. A.; Rezaei, B.; Nouroozi, S.; J. Braz. Chem. Soc. 2009, 20, 288.

4. Nelson, D. L.; Cox, M. M.; Lehninger Principles of Biochemistry, vol. 33; W. H. Freeman \& Company: New York, 2005.

5. Wang, Y.; Wang, J.; Yang, F.; Yang, X.; Anal. Sci. 2010, 26, 545.

6. Bamdad, F.; Khorram, F.; Samet, M.; Bamdad, K.; Sangi, M. R.; Allahbakhshi, F.; Spectrochim. Acta, Part A 2016, 161, 52.

7. Petrova, A. V.; Ishimatsu, R.; Nakano, K.; Imato, T.; Vishnikin, A. B.; Moskvin, L. N.; Bulatov, A. V.; J. Anal. Chem. 2016, 71, 172.

8. Lima, M. B.; Barreto, I. S.; Andrade, S. I. E.; Almeida, L. F.; Araújo, M. C. U.; J. Braz. Chem. Soc. 2014, 25, 1638.

9. Chwatko, G.; Kuźniak, E.; Kubalczyk, P.; Borowczyk, K.; Wyszczelska-Rokiel, M.; Głowacki, R.; Anal. Methods 2014, 6, 8039 .

10. Deáková, Z.; Ďuračková, Z.; Armstrong, D. W.; Lehotay, J.; J. Chromatogr. A 2015, 1408, 118.

11. Perevezentseva, D. O.; Gorchakov, E. V.; J. Solid State Electrochem. 2012, 16, 2405.

12. Cumba, L. R.; Bicalho, U. D. O.; do Carmo, D. R.; Int. J. Electrochem. Sci. 2012, 7, 4465.

13. Tao, Y.; Zhang, X.; Wang, J.; Wang, X.; Yang, N.; J. Electroanal. Chem. 2012, 674, 65.

14. Corrêa, C. C.; Jannuzzi, S. A. V.; Santhiago, M.; Timm, R. A.; Formiga, A. L. B.; Kubota, L. T.; Electrochim. Acta 2013, 113, 332.

15. Silva, C. C. C.; Breitkreitz, M. C.; Santhiago, M.; Corrêa, C. C.; Kubota, L. T.; Electrochim. Acta 2012, 71, 150.

16. Norouzi, B.; Gorji, A.; Ionics 2019, 25, 797.

17. Huang, Y. L.; Khoo, S. B.; Yap, M. G. S.; Electroanalysis 1994, 6,1077 .

18. Han, J.; Wang, Q.; Zhai, J.; Han, L.; Dong, S.; Analyst 2015, 140, 5295 .

19. Maruta, A. H.; Paixão, T. R. L. C.; Fuel 2012, 91, 187.

20. Colón, L. A.; Dadoo, R.; Zare, R. N.; Anal. Chem. 1993, 65, 476. 
21. Mendes, R. K.; Claro-Neto, S.; Cavalheiro, E. T. G.; Talanta 2002, 57, 909.

22. Mendes, R. K.; Cervini, P.; Cavalheiro, E. T. G.; Talanta 2006, 68, 708 .

23. Cervini, P.; Cavalheiro, E. T. G.; Anal. Lett. 2008, 41, 1867.

24. Farmacopéia Brasileira, vol. 1; ANVISA: Brasília, 2010, p. 546.

25. Bruins, P. F.; Polyurethane Technology; Interscience Publishers: New York, 1969.

26. Mosbach, M.; Laurell, T.; Nilsson, J.; Csöregi, E.; Schuhmann, W.; Anal. Chem. 2001, 73, 2468.

27. Bard, A. J.; Faulkner, L. R.; Electrochemical Methods: Fundamentals and Applications; Wiley: New York, 1980.

28. Trovati, G.; Sanches, E. A.; Claro Neto, S.; Mascarenhas, Y. P.; Chierice, G. O.; J. Appl. Polym. Sci. 2010, 115, 263.

29. dos Santos, W. T. P.; Azevedo, E. F.; Richter, E. M.; de Albuquerque, Y. D. T.; Quim. Nova 2009, 32, 2412.

30. Xi, L.; Wang, F.; Zhu, Z.; Huang, Z.; Zhu, Y.; Talanta 2014, $119,440$.

31. Prabhu, S. V.; Baldwin, R. P.; Anal. Chem. 1989, 61, 2258.

32. Pyun, C.-H.; Park, S.-M.; J. Electrochem. Soc. 1986, 133, 2024.

33. Kano, K.; Torimura, M.; Esaka, Y.; Goto, M.; Ueda, T.; J. Electroanal. Chem. 1994, 372, 137.

34. Rigo, A.; Corazza, A.; Di Paolo, M. L.; Rossetto, M.; Ugolini, R.; Scarpa, M.; J. Inorg. Biochem. 2004, 98, 1495.

35. da Silva, J. L.; Beluomini, M. A.; Sedenho, G. C.; Stradiotto, N. R.; Microchem. J. 2017, 134, 374.

36. Luo, P.; Prabhu, S. V.; Baldwin, R. P.; Anal. Chem. 1990, 62, 752.
37. Barsoukov, E.; Macdonald, J. R.; Impedance Spectroscopy: Theory, Experiment, and Applications; John Wiley \& Sons: Hoboken: New Jersey, 2005.

38. Petrović, M. B.; Radovanović, M. B.; Simonović, A. T.; Milić, S. M.; Antonijević, M. M.; Int. J. Electrochem. Sci. 2012, 7, 9043.

39. Christian, G. D.; Purdy, W. C.; J. Electroanal. Chem. 1962, 3, 363.

40. Enriquez, J. S.; Yu, M.; Bouley, B. S.; Xie, D.; Que, E. L.; Dalton Trans. 2018, 47, 15024.

41. Huerta-Aguilar, C. A.; Thangarasu, P.; Mora, J. G.; J. Mol. Struct. 2018, 1157, 660.

42. Abd El Haleem, S. M.; Ateya, B. G.; J. Electroanal. Chem. 1981, 117, 309.

43. Drogowska, M.; Brossard, L.; Ménard, H.; J. Electrochem. Soc. 1992, 139, 2787.

44. Palmer, D. A.; J. Solution Chem. 2011, 40, 1067.

45. Long, G. L.; Winefordner, J. D.; Anal. Chem. 1983, 55, 713.

46. Liu, J.; Itoh, J. I.; Talanta 2006, 70, 791.

47. Waseem, A.; Yaqoob, M.; Nabi, A.; Luminescence 2008, 23, 144.

48. Possari, R.; Carvalhal, R. F.; Mendes, R. K.; Kubota, L. T.; Anal. Chim. Acta 2006, 575, 172.

49. Bulatov, A. V.; Petrova, A. V.; Vishnikin, A. B.; Moskvin, L. N.; Microchem. J. 2013, 110, 369.

Submitted: May 3, 2019

Published online: August 12, 2019 